\title{
A SiGe 3-stage LNA for automotive radar application from 76 to $81 \mathrm{GHz}$
}

\author{
Vadim Budnyaev ${ }^{*}$ and Valeriy Vertegel \\ SevSU Engineering Center Ltd, Sevastopol State University, Sevastopol, Russia
}

\begin{abstract}
This paper presents the simulation results of the W-band 3stage low noise amplifier which is designed in $0.13 \mu \mathrm{m}$ SiGe BiCMOS technology. The LNA achieves a peak $\mathrm{S}_{21}$ of $24.1 \mathrm{~dB}$ and noise figure of $6 \mathrm{~dB}$ at $80 \mathrm{GHz}$ with $3 \mathrm{~dB}$ bandwidth of $14 \mathrm{GHz}$ from 73 to $87 \mathrm{GHz}$. $\mathrm{S}_{11}$ is better than $11 \mathrm{~dB}$. The simulated input $1 \mathrm{~dB}$ compression point is $-23 \mathrm{dBm}$ at $80 \mathrm{GHz}$ with low power consumption of $26 \mathrm{~mW}$ from $1.2 \mathrm{~V}$ voltage supply. Layout area is $0.36 \mathrm{~mm}^{2}$.
\end{abstract}

\section{Introduction}

Low noise amplifier (LNA) is the key element of the receiving path of any transceiver. The function of the LNA is pre-amplification of weak signals induced in the antenna without significantly degrading the signal-to-noise ratio. W-band LNAs are used in radars for various purposes $(76-77 \mathrm{GHz}$ long range automotive radars for adaptive cruise control and collision avoidance, 77-81 GHz short range parking radars [1], radars for non-contact level measurement [2], etc.), as well as in high speed wireless communication links with data rates up to $80 \mathrm{Gbit} / \mathrm{s}[3]$.

An important condition for the development of W-band systems is the emergence of electronic components and devices with acceptable parameters and cost. This paper presents the simulation results of the W-band LNA for radar application from 76 to $81 \mathrm{GHz}$ which is designed in $0.13 \mu \mathrm{m}$ SiGe BiCMOS technology process with current-gain cutoff frequency/maximum oscillation frequency $\left(f_{\mathrm{T}} / f_{\max }\right)$ of $300 / 500 \mathrm{GHz}$.

\section{Amplifier design}

Fig. 1 shows a detailed schematic diagram of W-band low noise amplifier with device parameters, supply and bias voltages. The LNA consists of 3-stage using cascode topology to reduce the influence of the Miller effect and obtain high gain.

The technique described in [4] was used for the simultaneous optimal matching of noise and input impedance. All transistors biased at current density that minimizes noise figure (NF). Transistor sizes are selected such that the real part of the optimum noise impedance is approximately equal to the source impedance at the $80 \mathrm{GHz}$. To obtain the maximum power transfer the LNA input impedance is matched to the source impedance $(50 \Omega)$. Microstrip

* Corresponding author: vadim.budnyaev@yandex.ru 
transmission lines (TL) in combination with integrated MIM capacitors are used as matching elements. TL are based on microstrip geometry (top and bottom metal layers). The sizes of TLs are summarized in Table 1.

The supply voltage is $1.2-1.8 \mathrm{~V}$ while the base voltage of transistors Q1, Q3, Q5 is $0.9 \mathrm{~V}$ which leads to the collector currents of about 7-8 mA. According to simulation, obtained current density is optimal for achieving low NF and high gain.

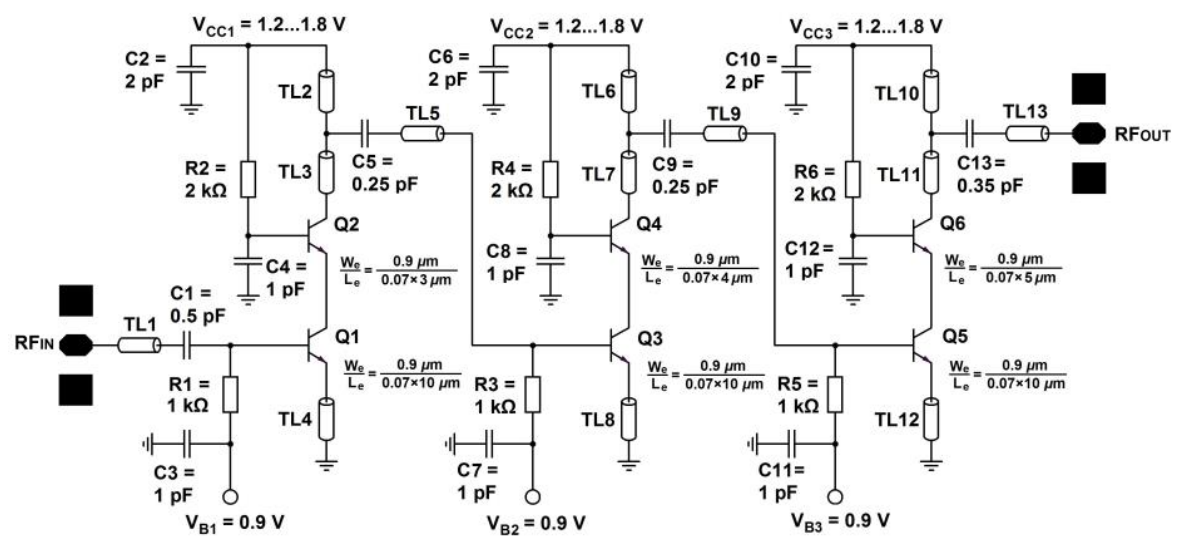

Fig. 1. Schematic of the 3-stage cascode LNA.

Table 1. Summary of the size of all TL.

\begin{tabular}{|c|c|c|}
\hline Microstrip TL & Length $(\boldsymbol{\mu m})$ & Width $(\boldsymbol{\mu m})$ \\
\hline TL1 & 70 & 7 \\
\hline TL2, TL6, TL10 & 40 & 15 \\
\hline TL3, TL7, TL11 & 85 & 15 \\
\hline TL4, TL8, TL12 & 30 & 15 \\
\hline TL5, TL9, TL13 & 90 & 7 \\
\hline
\end{tabular}

The layout of the mm-wave LNA is shown in Fig. 2. It occupies $740 \times 480 \mu \mathrm{m}$ $\left(0.36 \mathrm{~mm}^{2}\right)$ with pads and $563 \times 308 \mu \mathrm{m}\left(0.17 \mathrm{~mm}^{2}\right)$ without pads. Contact pads have dimensions of $80 \times 80 \mu \mathrm{m}$. Distance between their centers is $150 \mu \mathrm{m}$ (standart probe station pitch). Input and output RF pads were custom designed with the dimensions $53.33 \times 80 \mu \mathrm{m}$ to reduce parasitic capacitances, and also the edges were trimmed to further decrease the parasitic capacitance.

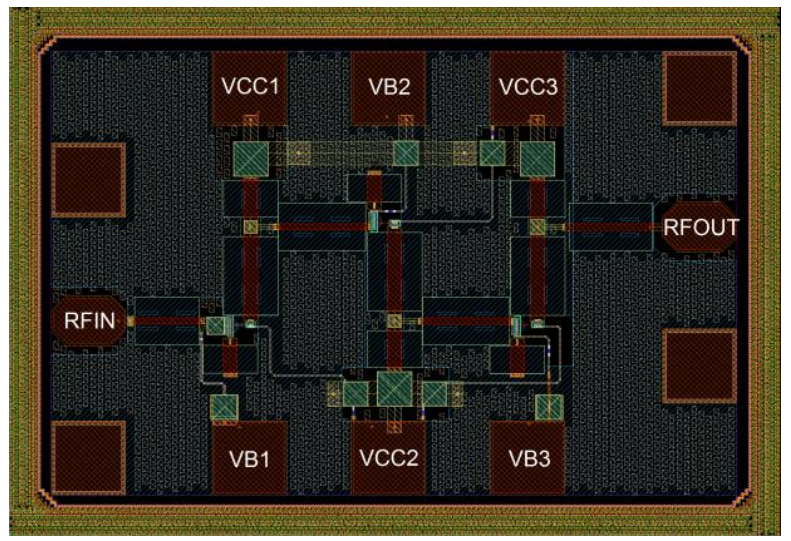

Fig. 2. Full layout of the 3-stage cascode LNA. 


\section{Simulation results}

In the W-band, the pads capacitance and package parasitic elements cannot be neglected in the simulation process. The paper [5] presents the results of measurements of flip-chip ball grid array (FCBGA) package parasitic resistances, capacitances and inductances. Using this data and equivalent circuit for FCBGA-package interconnect effects from [6], a virtual test bench was designed for more correct LNA simulation.

The simulated $S_{21}$ and $S_{11}$ versus frequency at different supply voltages are shown in Fig. 3. The LNA at standart $1.2 \mathrm{~V}$ has a peak gain of $24.1 \mathrm{~dB}$ at $81 \mathrm{GHz}$ with $3 \mathrm{~dB}$ bandwidth (BW) of 73-87 GHz. The $S_{11}$ is less than -10 for $70-110 \mathrm{GHz}$. The simulated $S_{22}$ (not shown) is less than $-7 \mathrm{~dB}$ at $3 \mathrm{~dB} \mathrm{BW}$. At supply voltage $1.8 \mathrm{~V}$ parameters change slightly ( $3 \mathrm{~dB}$ BW expands to $16 \mathrm{GHz}, S_{21}>20.5 \mathrm{~dB}, S_{11}<-9.5 \mathrm{~dB}$ ).



(a)

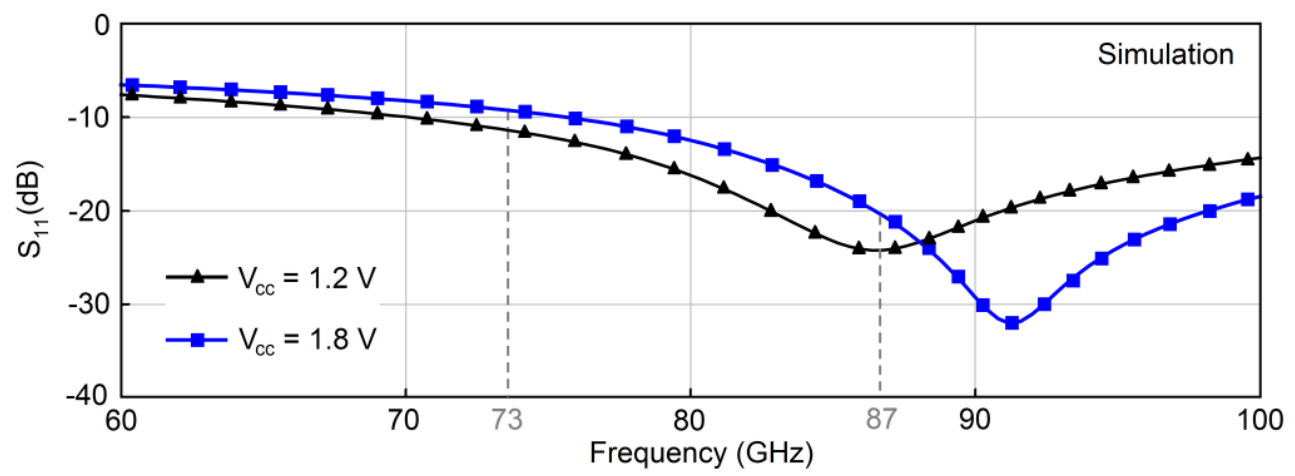

(b)

Fig. 3. Simulated $S_{21}$ (a) and $S_{11}$ (b) at different supply voltages.

Fig. 4 shows the simulated NF versus frequency characteristic at different temperatures $\left(-40{ }^{\circ} \mathrm{C}, 27^{\circ} \mathrm{C}\right.$ and $\left.125^{\circ} \mathrm{C}\right)$ and supply voltages $(1.2 \mathrm{~V}$ and $1.8 \mathrm{~V})$. The LNA achieves NF of 5.5-6.6 dB for frequencies $73-87 \mathrm{GHz}$ at standart $1.2 \mathrm{~V}$ and $27^{\circ} \mathrm{C}$. As the temperature rises, the noise figure increases as expected, but remains below $10 \mathrm{~dB}$ at $125^{\circ} \mathrm{C}$ and $1.8 \mathrm{~V}$. The amplifier demonstrates minimum NF of $3.6 \mathrm{~dB}$ at $73 \mathrm{GHz}$ and $-40{ }^{\circ} \mathrm{C}$.

The minimum achievable noise figure $\left(\mathrm{NF}_{\min }\right)$ is less than $\mathrm{NF}$ on average by $0.5 \mathrm{~dB}$ at $27^{\circ} \mathrm{C}$ (not shown).

Fig. 5 shows the simulated input $1 \mathrm{~dB}$ compression point $\left(I P_{1 \mathrm{~dB}}\right)$ versus frequency from 73 to $87 \mathrm{GHz}$ at $1.2 \mathrm{~V}$ and $1.8 \mathrm{~V}$ supply voltages. $I P_{1 \mathrm{~dB}}$ is more than $-23.7 \mathrm{dBm}$. 




Fig. 4. Simulated NF versus frequency characteristics at different temperatures and supply voltages.

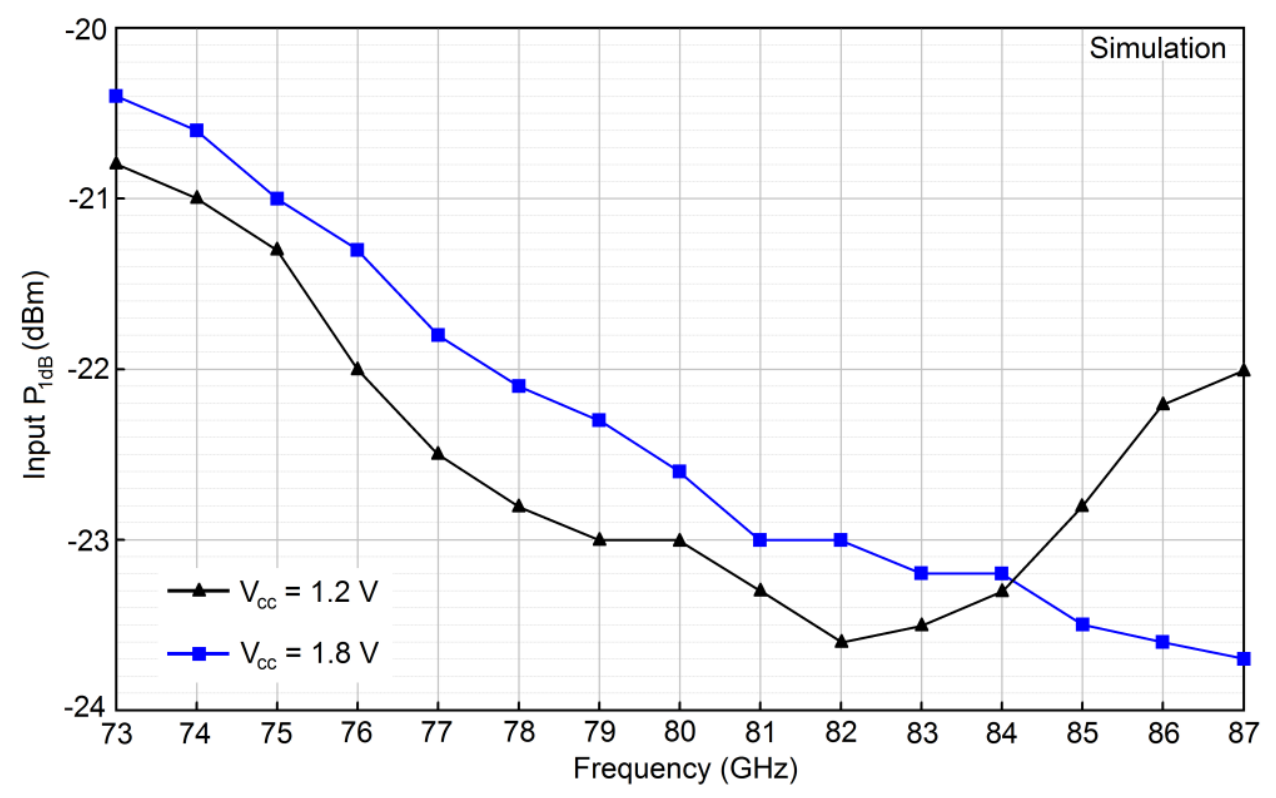

Fig. 5. Simulated $I P_{1 \mathrm{~dB}}$ versus frequency at different supply voltages.

Table 2 compares the simulated LNA with other CMOS and BiCMOS amplifiers at similar operating frequencies. As in [7-10], a figure of merit (FoM) was applied to for evaluating the performance of wideband LNAs. FoM takes the main LNA parameters and defined as

$$
F_{O M}=\frac{S_{21} \cdot B W}{(F-1) \cdot P_{D C}},
$$


where $S_{21}$ is the average power gain in magnitude; $B W$ is the $3-\mathrm{dB}$ bandwidth in $\mathrm{GHz} F$ is the noise figure in magnitude, and $P_{D C}$ is the power consumption in $\mathrm{mW}$.

Table 2. Summary of the simulated W-band LNA and comparison to state-of-the-art mm-wave LNAs.

\begin{tabular}{|c|c|c|c|c|c|}
\hline $\begin{array}{c}\text { Year } \\
\text { [Reference] }\end{array}$ & $\begin{array}{c}\mathbf{2 0 1 0} \\
{[\mathbf{1 1 ]}}\end{array}$ & $\begin{array}{c}\mathbf{2 0 1 2} \\
{[\mathbf{1 2 ]}}\end{array}$ & $\begin{array}{c}\mathbf{2 0 1 5} \\
{[\mathbf{1 3 ]}}\end{array}$ & $\begin{array}{c}\mathbf{2 0 1 8} \\
{[\mathbf{1 4}]}\end{array}$ & $\begin{array}{c}\mathbf{2 0 1 9} \\
\text { [This work]* }\end{array}$ \\
\hline $\begin{array}{c}0.18 \mu \mathrm{m} \\
\text { Technology } \\
\text { BiCMOS }\end{array}$ & $\begin{array}{c}0.25 \mu \mathrm{m} \\
\text { SiGe-C } \\
\text { BiCMOS }\end{array}$ & $\begin{array}{c}65 \mathrm{~nm} \\
\text { CMOS }\end{array}$ & $\begin{array}{c}45 \mathrm{~nm} \\
\text { CMOS SOI }\end{array}$ & $\begin{array}{c}0.13 \mu \mathrm{m} \\
\text { SiGe BiCMOS }\end{array}$ \\
\hline $\begin{array}{c}3-\mathrm{dB} \mathrm{BW} \\
(\mathrm{GHz})\end{array}$ & $\begin{array}{c}14.5 \\
(69-83.5)\end{array}$ & $\begin{array}{c}12 \\
(66-78)\end{array}$ & $\begin{array}{c}15 \\
(69-84)\end{array}$ & $\begin{array}{c}16 \\
(80-96)\end{array}$ & $\begin{array}{c}14 \\
(73-87)\end{array}$ \\
\hline$S_{21}(\mathrm{~dB})$ & $13.1-14.5$ & $21.3-23$ & $11-13.1$ & $10-12$ & $21.1-24.1$ \\
\hline$S_{11}(\mathrm{~dB})$ & $<-8$ & $<-5$ & $<-10$ & $<-7$ & $<-11$ \\
\hline $\mathrm{NF}(\mathrm{dB})$ & 6.9 & $7.6-8.4$ & $7-7.2$ & $4.2-5.6$ & $5.5-6.6$ \\
\hline$I P_{1 \mathrm{~dB}}(\mathrm{dBm})$ & -11.4 & -18 & -16 & -21 & $-23(80 \mathrm{GHz})$ \\
\hline$P_{\mathrm{DC}}(\mathrm{mW})$ & 37 & 40 & 24 & 4.7 & 26 \\
\hline Area $\left.(\mathrm{mm})^{2}\right)$ & 0.41 & 0.79 & 0.17 & 0.42 & 0.36 \\
\hline $\begin{array}{c}F o M \\
(\mathrm{GHz} / \mathrm{mW})\end{array}$ & 0.49 & 0.73 & 0.7 & 2.01 & 1.07 \\
\hline
\end{tabular}

*Simulation results

\section{Conclusion}

The W-band 3-stage cascode low noise amplifier using $0.13 \mu \mathrm{m}$ SiGe BiCMOS process with $f_{\mathrm{T}} / f_{\max }$ of $300 / 500 \mathrm{GHz}$ is presented in this paper. The LNA has a high $S_{21}$ of $>21 \mathrm{~dB}$, $\mathrm{NF}$ of 5.5 to $6.6 \mathrm{~dB}$ in $3-\mathrm{dB} \mathrm{BW}$ of $14 \mathrm{GHz}$. The $S_{11}$ is lower than $-10 \mathrm{~dB}$ from 70 to $110 \mathrm{GHz}$. The simulated input $I P_{1 \mathrm{~dB}}$ is $-23 \mathrm{dBm}$ at $80 \mathrm{GHz}$. The supply voltage and power consumption are $1.2 \mathrm{~V}$ and $26 \mathrm{~mW}$, respectively. The layout area is $0.36 \mathrm{~mm}^{2}$ with all of the contact pads and $0.17 \mathrm{~mm}^{2}$ without pads.

The amplifier is expected to integrate in the front-end transceiver of single-chip automotive 77-81 GHz short range radar.

\section{References}

1. S. T. Nicolson, K. H. K. Yau, S. Pruvost, V. Danelon, P. Chevalier, P. Garcia, A. Chantre, B. Sauteuil, S. P. Voinigescu, A Low-Voltage SiGe BiCMOS 77-GHz Automotive Radar Chipset, IEEE Transactions on Microwave Theory and Techniques, 5, pp. 1092-1104 (2008)

2. Impact of Level Probing Radars using Ultra-Wideband Technology on Radiocommunications Services (ECC, Rottach-Egern, 2010)

3. F. Boes, J. Antes, T. Messinger, D. Meier, R. Henneberger, A. Tessmann, I. Kallfass, Multi-Gigabit E-band Wireless Data Transmission, 2015 IEEE MTT-S International Microwave Symposium, pp. 1-4 (2015)

4. S. T. Nicolson, S. P. Voinigescu, Methodology for Simultaneous Noise and Impedance Matching in W-Band LNAs, IEEE Compound Semiconductor Integrated Circuit Symposium, pp. 279-282 (2006) 
5. T. Y. Tee, G. Siew, H. Chen, S. Soh, I. S. Kang, J. H. Kim, T. K. Lee, B. L. Ser, H. S. Ng, G. Hoe, S. Gao, Development of Low-cost Wafer Level Package through Integrated Design and Simulation Analysis, 2011 12th International Conference on Electronic Packaging Technology and High Density Packaging, pp. 549-555 (2011)

6. K.-C. Lu, F.-Y. Han, T.-S. Horng, J. Lin, H.-H. Cheng, C.-T. Chiu, C.-P. Hung, Packaging Effects on a CMOS Low-Noise Amplifier: Flip-chip versus Wirebond, 2009 59th Electronic Components and Technology Conference, pp. 2064-2069 (2009)

7. Y.-S. Lin, G.-L. Lee, C.-C. Wang, C.-C. Chen, A $21.1 \mathrm{~mW} 6.2 \mathrm{~dB}$ NF $77 \sim 81 \mathrm{GHz}$ CMOS Low-Noise Amplifier with $13.5 \pm 0.5 \mathrm{~dB}$ S21 and Excellent Input and Output Matching for Automotive Radars, 2014 IEEE Radio and Wireless Symposium (RWS), pp. 73-75 (2014)

8. C. J. Lee, H. J. Lee, J. G. Lee, T. H. Jang, C. S. Park, A W-band CMOS Low power Wideband Low Noise Amplifier With $22 \mathrm{~dB}$ Gain and 3dB bandwidth of $20 \mathrm{GHz}$, 2015 Asia-Pacific Microwave Conference (APMC), pp. 1-3 (2015)

9. Y.-S. Lin, C.-Y. Lee, $9.99 \mathrm{~mW} 4.8 \mathrm{~dB}$ NF 57-81 GHz CMOS low-noise amplifier for $60 \mathrm{GHz}$ WPAN system and $77 \mathrm{GHz}$ automobile radar system, Microwave and Optical Technology Letters, 3, pp. 594-600 (2015)

10. G. Feng, C. C. Boon, F. Meng, X. Yi, K. Yang, C. Li, H. C. Luong, Pole-Converging Intrastage Bandwidth Extension Technique for Wideband Amplifiers, IEEE Journal of Solid-State Circuits, 3, pp. 769-780 (2017)

11. A. Y. K. Chen, Y. Baeyens, Y. K. Chen, J. Lin, A Low-Power Linear SiGe BiCMOS Low-Noise Amplifier for Millimeter-Wave Active Imaging, IEEE Microwave and Wireless Components Letters, 4, pp. 103-105 (2010)

12. A. C. Ulusoy, M. Kaynak, T. Purtova, B. Tillack, H. Schumacher, A 60 to $77 \mathrm{GHz}$ Switchable LNA in an RF-MEMS Embedded BiCMOS Technology, IEEE Microwave and Wireless Components Letters, 8, pp. 430-432 (2012)

13. D. Pepe, D. Zito, $72 \mathrm{GHz}$ CMOS LNA with Transformer-based Input Integrated Matching, 2015 26th Irish Signals and Systems Conference (ISSC), pp. 1-5 (2015)

14. L. Gao, Q. Ma, G. M. Rebeiz, A $4.7 \mathrm{~mW}$ W-Band LNA with $4.2 \mathrm{~dB}$ NF and $12 \mathrm{~dB}$ Gain Using Drain to Gate Feedback in 45nm CMOS RFSOI Technology, IEEE Radio Frequency Integrated Circuits Symposium, pp. 280-283 (2018) 